\title{
EUTOMIA
}

Revista de Literatura e Linguística

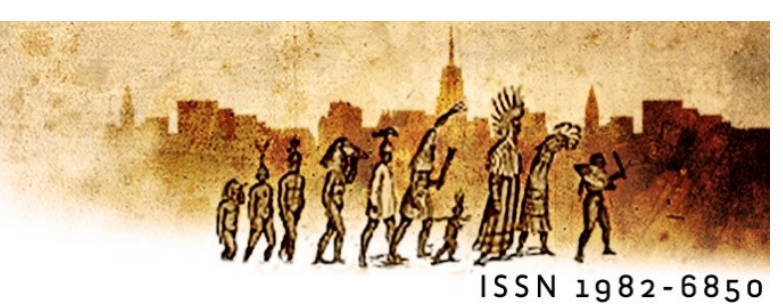

\section{Escrita ação, escrita corpo}

\section{Action writing, action body}

Lia Duarte Motai (UFJF)

Resumo: Em $A$ hora da estrela, último romance de Clarice Lispector, de 1977, o narrador Rodrigo S.M afirma que da junção de palavras que formam frases surge um sentido secreto, e que ele escreve com o corpo. Esse sentido secreto parece estar próximo do que Jacques Rancière chama de política da arte. Para o teórico, a arte possui uma política própria, que concorre com a disciplina política e que é anterior à vontade dos artistas. Desse modo, a arte não produz conhecimento para a política, mas sim dissensos, uma experiência específica, fruto do engendramento entre o visível e o não visível, o dizível e o não dizível. O que vale ressaltar é que a tensão imposta não se resolve, ela é parte do espaço sensível comum. Trata-se, então, de pensar como esses corpos estão imbricados na escrita, partes de um ato que se dá no indecidível da política da arte. A literatura envolve o corpo e não deve falar, especificamente, sobre situações políticas para ser política, não deve falar, especificamente, sobre a existência ou a construção/ ocupação humana do mundo para ser considerada pensamento. A escrita é política ao embaralhar gêneros, discursos, assuntos, línguas, lugares. A proposta deste trabalho é pensar este corpo presente no romance de Clarice Lispector como ação política.

Palavras-chave: escrita; corpo; política; Clarice Lispector; Jacques Rancière.

Abstract: In A hora da estrela, Clarice Lispector's last novel, from 1977, the narrator Rodrigo S.M affirms that from the junction of words that form sentences a secret meaning emerges, and that he writes with his body. This secret meaning seems to be close to what Jacques Rancière calls art politics. For the theorist, art has its own policy, which competes with the political discipline and which predates the artists' will. In this way, art does not produce knowledge for politics, but rather dissent, a specific experience, which results from the engendering between the visible and the non-visible, the sayable and the non-sayable. What is worth mentioning is that the imposed tension is not resolved. This tension is part of the common sensible space. It is a question, then, of thinking about how these bodies are intertwined in writing, parts of an act that occurs in the undecidable politics of art. Literature involves the body and must not 
speak, specifically, about political situations to be political, must not speak, specifically, about the existence or the human construction/occupation of the world to be considered thought. Writing is political as it shuffles genres, speeches, subjects, languages, places. The purpose of this work is to think of this body present in the novel by Clarice Lispector as a political action.

Keywords: writing; body; politics; Clarice Lispector; Jacques Rancière.

\section{Corpo em preparo}

Em A hora da estrela, último romance de Clarice Lispector, de 1977, o narrador Rodrigo S.M. afirma que, para escrever, seu material básico é a palavra, e que é da junção de palavras, formando frases, que surge um sentido secreto. A palavra é ação, pois a palavra muda a vida. Macabéa, ao sair da cartomante, já é outra pessoa. Antes mesmo de qualquer das previsões ocorrer ou não, as palavras da cartomante já a haviam transformado, enchendo-a de esperança e de futuro.

O narrador nos avisa também que não é um intelectual, que ele se sensibiliza, e escreve com o corpo. "Estou esquentando o corpo para iniciar, esfregando as mãos uma na outra para ter coragem" (LISPECTOR, 1990, p. 28). É preciso todo o seu corpo para escrever, pois a história que ele conta lhe é imposta num milésimo relance em que seus olhos se cruzam com os de uma nordestina. Enquanto caminha pelas ruas entre tantas pessoas, há um instante fatal e passageiro em que é capturado. E não pode mais voltar atrás. Não pode esquecer.

O preparo do corpo demanda uma atenção total, não do intelecto, mas de todos os seus sentidos. Uma atenção radial, em todas as direções. ${ }^{1}$ Para Michel Serres, a filosofia passa pelo corpo. E a singularidade do corpo não está dada, não está assegurada, é tida pelas transformações, indícios e suas adequações possíveis.

Na abertura da versão argentina de Variações sobre o corpo, de Michel Serres, Adrián Cangi explica que a escrita, para o filósofo, é uma forma de colocar o corpo em uma flexibilidade sensível, "a escrita como gesto de estilo é um ato de resistência para não impor uma forma predeterminada a uma matéria viva". (CANGI, 2011, p. 25, tradução nossa).

\footnotetext{
${ }^{1}$ Trata-se de uma referência à filosofia de Michel Serres. Em sua proposta, o corpo todo se engaja no conhecimento, na aprendizagem, na aquisição filosófica: "Descontraído, como que livre, o corpo faz a mímica do particípio futuro, preparado para se distender: para o alto, rente à terra ou à meia altura, nos dois sentidos, esquerda e direita; na direção do centro do plexo solar, uma plataforma estrelada lança seus ramos virtuais em todos os sentidos ao mesmo tempo, como um buquê de axônios" (SERRES, 1993, p. 16).
} 
A escrita de Serres parte do concreto do mundo, desde a montanha, a bola, a rede, até a guerra e a biblioteca. Tudo dá possíveis ao homem. A escrita vem da junção de diferentes experiências: a experiência do corpo que se arrisca, que treina, que lê, que adoece. É necessário exigir dele, fazê-lo alterar suas reações habituais. Michel Serres, por exemplo, começou a escalar montanhas. Ele sabe que, ao colocar o corpo em risco, há o perigo da morte. Ele reconhece que não se trata de uma equação exata, que há sempre o risco que a doença mate, que a defesa do corpo ativo e atento, que encontra saída nas adversidades, possa ser usada para "o darwinismo social e a exploração dos homens por seus semelhantes" (SERRES, 2011, p. 56). Por isso, a importância de saber ouvir o corpo, qualquer caminho que não seja o da manutenção da vida é um indício de que o entendemos mal.

O narrador de Clarice Lispector também tem a necessidade de preparar o corpo para a escrita, tem a necessidade de incorporar o modo de vida dela, pois, para escrever sobre Macabéa, será preciso sentir no corpo a inanição, a escassez de sono, a carência dos hábitos que se tornaram básicos. Rodrigo S.M. não é um escritor que demanda apenas o isolamento e a concentração para escrever. Ele precisa sentir-se como Macabéa, por isso, terá que fazer alterações em seu próprio corpo, logo, na maneira em que vive. Só assim poderá lidar com as palavras. Já Macabéa, não por uma relação de causa-consequência, a relação acontece pela ação das palavras em seu corpo. É pela escuta que ela vivencia o mundo.

\section{Corpo em aquisição}

Em $A$ hora da estrela, a escrita é tarefa manual e insistente, que exige o corpo todo. A escrita é comparada ao quebrar de rochas. No início, Rodrigo S.M. declara que entre ele e Macabéa não há nada em comum, de modo que é preciso privar-se de pessoas, de descanso, de cuidado, fechar-se no quarto, descuidar da aparência, sentir a fome e a exaustão, deixar que o corpo vivencie cada um desses estados para que possa escrever: "Agora não é confortável: para falar da moça tenho que não fazer a barba durante dias e adquirir olheiras escuras por dormir pouco, só cochilar de pura exaustão, sou um trabalhador. Além de vestir-me com roupa velha rasgada. Tudo isso para me pôr no nível da nordestina" (LISPECTOR, 1990, p. 34). 
No entanto, no decorrer do romance, narrador e personagem parecem se aproximar, compartilhar o modo de sentir e compreender o mundo. Quando Macabéa está caída no meio da rua, ainda viva e rodeada por pessoas desconhecidas, Rodrigo S.M. afirma:

Mas quem sou eu para censurar os culpados? O pior é que preciso perdoálos. É necessário chegar a tal nada que indiferentemente se ame ou não se ame o criminoso que nos mata. Mas não estou seguro de mim mesmo: preciso perguntar, embora não saiba a quem, se devo mesmo amar aquele que me trucida e perguntar quem de vós me trucida. E minha vida, mais forte do que eu, responde que quer porque quer vingança e responde que devo lutar como quem se afoga, mesmo que eu morra depois. Se assim é, que assim seja. (LISPECTOR, 1990, p. 100)

Em ambos os momentos, o corpo está ativo e presente, parte crucial da escrita. É preciso vivenciá-la no corpo. E a escrita torna-se a única possibilidade de vida, a única coisa a fazer no mundo. A escrita confirma a sua existência: "Quanto a mim, só me livro de ser apenas um acaso porque escrevo, o que é um ato que é um fato" (LISPECTOR, 1990, p. 52).

O sentido secreto de que fala o narrador parece estar próximo do que Jacques Rancière chama de política da arte, algo que, entre outras coisas, está além da vontade do autor/artista. Neste caso, não se trata de a arte ter um cunho político ou social, e sim de produzir experiências sensório-motoras únicas, de deslocar distinções e hierarquias. Para tanto, é preciso entender que o conceito de escrita é político, porque a escrita é o ato de desdobramento incessante, ela não para de significar algo novo, ela não deixa as palavras repousadas. A literatura coloca em desordem as palavras, mexe com os referentes e com os enunciados mudos/falantes.

Rancière afirma:

Há democracia - e política, consequentemente, - porque há palavras sobrando, palavras sem referente e enunciado sem pais, que desfazem qualquer lei de correspondência entre a ordem das palavras e a das coisas. A deserção democrática da incorporação comunitária é solidária à deserção literária da encarnação. Literatura e democracia são dois modos de invenção de quase-corpos ou de incorpóreos cujo dispositivo fragiliza as encarnações e as identificações que ligam uma ordem do discurso a uma ordem das condições. (RANCIÈRE, 2017, p. 18)

É que a literatura consegue dar corpo às palavras. Além disso, ela envolve o corpo em sua feitura e na leitura. Ela se dissemina entre corpos. Por isso, o conceito de escrita é político também por sua disjunção, por sua possibilidade de separação e de alternância, ao 
ligar estabelecendo alternância ou distinção. Portanto, ao se disseminar, ela não iguala, mas produz dissenso.

Diferente do narrador, Macabéa quase não tem corpo, quase não tem vida. Macabéa é um "corpo cariado", o espelho parece não refletir a sua imagem, "é que lhe falta gordura e seu organismo estava seco". Por lhe faltar corpo, Macabéa é também incompetente para a vida. Daí, não saber de si, não saber que é infeliz, porque não sabe nem que pode desejar algo, além de vida. Daí, não fazer perguntas. "Mas a pessoa de quem falarei mal tem corpo para vender, ninguém a quer, ela é virgem e inócua, não faz falta a ninguém." (LISPECTOR, 1990, p. 28)

É pela escuta que Macabéa ganha corpo e deixa sua marca no mundo. O galo cantando a faz sentir nostalgia, a Rádio Relógio lhe dá a hora certa e cultura. Se o narrador, do início ao fim, insiste que esse livro é um silêncio, o que temos é um livro todo cheio de sons. Como se Macabéa fosse tomando conta dele, cada vez mais e mais. Macabéa gosta dos ruídos. É que ela apreende o mundo pelos ouvidos:

Ela era calada (por não ter o que dizer) mas gostava de ruídos. Eram vida. Enquanto o silêncio da noite assustava: parecia que estava prestes a dizer uma palavra fatal. Durante a noite na rua do Acre era raro passar um carro, quanto mais buzinassem, melhor para ela. Além desses medos, como se não bastassem, tinha medo grande de pegar doença ruim lá embaixo dela - isso, a tia Ihe ensinara. Embora os seus pequenos óvulos tão murchos. Tão, tão. Mas vivia em tanta mesmice que de noite não se lembrava do que acontecera de manhã. Vagamente pensava de muito longe e sem palavras o seguinte: já que sou, o jeito é ser. Os galos de que falei avisavam mais um repetido dia de cansaço. Cantavam o cansaço. E as galinhas, que faziam elas? Indagava-se a moça. (LISPECTOR, 1990, p. 49)

Para Marília Librandi, a literatura brasileira possui uma peculiaridade: a de estar atenta aos timbres, fruto de uma tradição cultural atenta à oralidade e à musicalidade. Já que o som reverbera, pode a literatura, neste caso, ser pensada como uma experiência sempre renovada a cada leitura e futura. Librandi explica que

a escrita de ouvido pode ser definida a partir de três vetores principais: um impulso musical não mimético que realça a qualidade dominante da escrita literária; um multilingualismo sonoro que produz a literatura como uma língua franca cosmopolita; e um espaço de escuta que se situa além das dicotomias letrado/não letrado; literatura/culturas orais; fala/escrita. (LIBRANDI, 2015, p. 133) 
Como Rancière, mas por um caminho próprio, Librandi concebe a literatura como algo capaz de interferência ética e política. Vale ressaltar suas palavras por serem de importância vital para a ideia defendida neste artigo:

Sugiro que se trata de uma ética de abrir os ouvidos para ouvir a voz, os sons, os ruídos, dos grupos que se situam fora do letramento oficial, e que se relacionaria com um engajamento literário dominante em ex-colônias nas quais uma cultura oral e musical predominante será transposta para a escrita literária, afetando-a. (LIBRANDI, 2015, p. 133)

Mais do que buscar qualidades na literatura brasileira que a distinga, há a compreensão de que a literatura pode mais, que, ao ressoar, ela quebra com a primazia da escrita sobre a oralidade, da voz de autoridade sobre a escuta, do intelecto sobre o corpo.

Em relação ao livro $A$ hora da estrela, a pesquisadora destaca uma escrita em eco. Clarice Lispector nos apresenta a voz masculina que contará a história, via Rodrigo S.M. Para Librandi, o que temos no livro são muitos sons ressoando: a música que o permeia desde a "Dedicatória do autor", que cita Clara e Robert Schumann, Beethoven, Bach, Chopin, Stravinsky, Strauss, Debussy, Marlos Nobre, Prokofiev, Carl Orff, Schönberg, até o som da Rádio Relógio, assim como a voz feminina de Clarice e a masculina do narrador fictício, até o final, quando se pode ouvir a "música antiga das palavras" e vidas que se acabam. Antes da morte, há um barulho do "grito estertorado da gaivota" ou do gato estraçalhando um rato, de um carro atingindo um corpo em alta velocidade. Com a morte de Macabéa, há a iminência do som. E há o silêncio.

Os cinco sentidos - Filosofia dos corpos misturados 1, de Michel Serres, é dividido em cinco partes, cada uma delas abordando os sentidos e o corpo de forma diferente da filosofia tradicional. Serres recorre aos mitos, à matemática, à história, ao seu próprio corpo e experiências para construir sua filosofia. No capítulo intitulado "Caixas", ele trata da escuta. Para ele, a busca pela saúde está relacionada ao silêncio, é preciso buscar o silêncio da língua. Sócrates falou até o instante de sua morte e, com isso, fez com que a filosofia estivesse ligada apenas à palavra. A linguagem reuniu grupos e coletivos que se encerram em suas próprias paredes, produzindo ruídos sem parar, sendo anestesiados por ela. Se não é possível ouvir, resta ver. $E$ toda a sociedade torna-se refém de um único sentido: a visão. Está dado, em muitas teorias e manuais de arte e de comunicação, o predomínio da imagem. Ver sobrepõe-se a todos os outros modos de perceber o mundo. 
Serres afirma: "Ver quer dizer saber, e saber reduz-se a dizer; ver ou viver e viver ou dizer. Não resta nada a dizer, e o olhar se fixa: nada a ver fora do dizível, não há nada fora do dizível. Quando fazes silêncio, não vês mais nada, resta morrer" (SERRES, 2001, p. 89).

A protagonista Macabéa quebra com esse paradigma. Novamente, ela apreende o mundo pela escuta. É importante repetir. Escutamos com o corpo todo. Sentimos a vibração de um som grave no corpo todo. Sentimos o agudo doer no ouvido. São os sons que permitem que Macabéa sinta e, consequentemente, que elabore pensamento, que questione e compreenda o mundo a seu redor. Assim, Olímpico, ao contar para Macabéa seu sonho de ficar rico, ouve: "- Não será somente visão?" e quando perguntada se não tinha preocupações, responde: "- Não, não tenho nenhuma. Acho que não preciso vencer na vida" (LISPECTOR, 1990, p. 66). Nos diálogos com Olímpico, vai ficando evidente o raciocínio pouco linear e nada causalista da personagem. Macabéa compreende o mundo, mas não consegue expressá-lo por meio de palavras:

- Por que é que você me pede tanta aspirina? Não estou reclamando, embora isso custe dinheiro.

- É para eu não me doer.

- Como é que é? Hein? Você se dói?

- Eu me dôo o tempo todo.

- Aonde?

- Dentro, não sei explicar. (LISPECTOR, 1990, p. 80)

Como aponta Michel Serres, a orelha pode se estender, pode detectar sons muito distantes. Como se fosse longe buscar algo que o corpo físico não alcança. Macabéa demora para conseguir se reconhecer no espelho. Em seu rosto, vê ferrugem. Os sons, no entanto, a enchem de vida. O galo a faz lembrar de Alagoas, a Rádio Relógio contém sons de gotas e anúncios, a música a faz dançar e sentir-se l-i-v-r-e uma única vez. As impressões de Macabéa são tão intensas que são definidas como explosões. E as explosões aparecem no texto entre parênteses.

Os parênteses permeiam toda a escrita. O sinal gráfico é utilizado para interromper o discurso e dizer algo diferente. Ou o sinal traz uma informação a mais, que acrescenta, amplia, mas não é essencial. O narrador Rodrigo S. M. reivindica a história que conheceremos, e desde o início nos informa que é ele quem a contará. No entanto, assim, como as explosões de Macabéa, seus sentimentos extremos são expressos por uma única palavra não essencial - afinal, a história é feita apenas de fatos e é preciso não ler outros 
autores para não contaminar com luxo a linguagem necessária -, o narrador também se coloca entre parênteses quando sente necessidade de interromper a história. Ele já não é mais o responsável por ela acontecer, não é mais o condutor. A história de Macabéa tornase mais e mais importante, assume o essencial a ser conhecido.

Jean-Luc Nancy, em seu ensaio sobre a escuta, parte da expressão "estar à escuta" para se perguntar:

Um dos aspectos da minha pergunta será então: de que segredo se trata quando se escuta propriamente, quer dizer quando nos esforçamos por captar ou por surpreender a sonoridade mais do que a mensagem? Que segredo se confia - que, por conseguinte, se torna também público -, quando escutamos, por eles mesmos, uma voz, um instrumento ou um barulho? E o outro aspecto, indissociável, será: o que é então ser à escuta, tal como se diz "ser no mundo"? O que é existir segundo a escuta, para ela e por ela, o que é que da experiência e da verdade aí se põe em jogo? O que é que aí se joga, o que é que aí ressoa, qual é o tom da escuta ou o seu timbre? Seria a própria escuta sonora? (NANCY, 2014, p. 15)

Macabéa existe pela escuta. É a escuta que a movimenta, que a faz compreender o mundo. É a escuta que a leva longe, onde as pernas não podem alcançar. É que Macabéa apreende o mundo pela escuta. Ainda que mero fio de sangue escorrendo pelos paralelepípedos, prestes a desaparecer com a chuva. Mas é a existência miúda dessa "caixinha de música meio desafinada" que permite que a literatura termine com um sim.

Apesar do narrador adiar e nos avisar porque demora para começar a história ou, como ele mesmo afirma, apresentar os fatos duros como pedras, desde o início nos dá pistas sobre o que vai acontecer. Diz que o som do violino tocado por "um homem magro", "de cara estreita e amarela como se ele já tivesse morrido" acompanhará toda a história. Diz que ninguém ensinaria Macabéa a morrer e que, na hora da morte, cada um vivencia seu instante de glória. O estrelato da morte e o violino voltam ao final do romance. O narrador nos prepara, desde o início, para a fatalidade, apesar de adiar ao máximo a morte da personagem.

Também o silêncio é anunciado do início ao fim do romance. Mas ele não ocorre. É que Macabéa enche a narrativa de sons, não de palavras. Como já dito, A hora da estrela é todo feito de música, desde a dedicatória. O rufar dos tambores anuncia a chegada da personagem ao texto e o violino acompanha toda a história. O vivo da grande ventania mistura-se aos últimos sons de ar que seu aparelho respiratório emite. E não só. O grito mudo se faz pelas sinestesias da linguagem: "o amargor da infância", "a voz crua", "a voz de 
cana rachada", "a palavra no escuro", "o surdo terremoto", "o destino que sussurra veloz e guloso".

Talvez porque, no seu interior, Macabéa já intuísse que o silêncio não existe. Em 1951, o compositor John Cage visitou a câmara anecoica da Universidade de Harvard, com o objetivo de experimentar o silêncio absoluto. Lá, ele percebeu que não há silêncio. O que pôde ouvir, nitidamente, foram os sons do próprio corpo que, no cotidiano barulhento, tornam-se abafados. Os sons grave e agudo de seus sistemas circulatório e nervoso, respectivamente.

O sentido secreto que busca o narrador de $A$ hora da estrela não seria o segredo presente na sonoridade de uma escuta de que fala Nancy? Não estaria Macabéa próxima de descobrir o segredo por meio de sua escuta insistente? Quando Olímpico a questiona sobre o seu nome, ela responde: "É verdade. Mas não sei o que está dentro do meu nome. Só sei que eu nunca fui importante..." (LISPECTOR, 1990, p. 73). Não estaria Macabéa adquirindo consciência social a cada nova experiência sonora?

A seguir, o narrador completa:

Aliás cada vez mais ela não se sabia explicar. Transformara-se em simplicidade orgânica. E arrumara um jeito de achar nas coisas simples e honestas a graça de um pecado. Gostava de sentir o tempo passar. Embora não tivesse relógio, ou por isso mesmo, gozava o grande tempo. Era supersônica de vida. Ninguém percebia que ela ultrapassava com sua existência a barreira do som. Para as pessoas outras ela não existia. (LISPECTOR, 1990, p. 80)

\section{Corpo em performance}

Se Macabéa apreende o mundo pela escuta, significa também dizer que ela aprende o mundo antes pelos sentidos do que pelo intelecto. É pelo corpo que se conhece o mundo. Tal compreensão sobre a protagonista possibilita uma aproximação entre sua forma de apreensão e a performance, como definida por Diana Taylor, professora do Departamento de Performance da Universidade de Nova York. Taylor vê na performance mais do que um campo artístico. A performance é, para ela, uma episteme, um modo de conhecer: "um sistema de aprendizagem, armazenamento e transmissão de conhecimento" (TAYLOR, 2013, p. 45). O conhecimento é transmitido e adquirido por todo o corpo.

Assim, é possível pensar em Macabéa não somente como a nordestina sem direito ao grito, mas aquela capaz de um estado crescente de aquisição de mundo, do outro, de si. 
Tudo pelo corpo. Pela escuta, ela conhece cada vez mais o mundo. Mais do que isso, é possível estender a ideia para a própria escrita de Clarice Lispector, já que seu narrador nos indica: "Verifico que escrevo de ouvido..." (LISPECTOR, 1990, p. 33). Marília Librandi nos mostra como o fazer artístico da autora de $A$ hora da estrela se caracteriza por ser uma escrita do improviso:

A hora da estrela se apresenta assim como um "livro inacabado", em processo de escritura, e toda a primeira parte é dedicada a uma autoexposição sobre a escrita do livro, como um ensaio metaficcional antes da ação da narrativa, que começa então de um salto: "O jeito é começar de repente assim como eu me lanço na água gélida do mar... Vou agora começar pelo meio dizendo que...". Em Lispector a improvisação vai tão longe que remete não apenas a um método, mas a um "modo de vida". (LIBRANDI, 2015, p. 141)

A arte performática tem a característica de não estar fechada, de não possuir uma obra pronta ou final a ser mostrada ao público, ela se faz no presente, com a participação do outro. Por isso, nunca está acabada, não pode ser repetida. É arte feita ao vivo em que o espaço e o corpo ganham destaque. Ela não busca chegar a um resultado, apenas fazer com que o espectador reavalie os conceitos de arte e sua relação com a cultura. Possui uma base anárquica, à medida que não se prende a nenhum dos preceitos presentes nas outras expressões artísticas, sendo, portanto, uma ação política.

Segundo Taylor, a performance difere do que é arquivo, cuja estrutura é rígida, como edifício, documento, osso, texto, fazendo parte do repertório, língua falada, dança, esporte, ritual. O repertório, por suas qualidades, está ligado ao efêmero e à presença física. Trata-se de uma memória incorporada e transmitida pelo corpo, via língua, dança, gesto, canto. A transmissão se dá entre corpos, os corpos que recebem o conhecimento o levarão adiante, guardado por meio de métodos mnemônicos.

Se a história de Macabéa nos chega pela escrita de Clarice Lispector, logo, o arquivo, ao abrir as páginas encontramos corpo, que está todo atento aos sons, repertório. E ainda que "inventada" e fictícia, Macabéa é viva, basta estar atento e preparado para reconhecê-la nas ruas. Macabéa é vida cheia de som, ainda que não possa dar o grito. Ela vive na literatura para que possamos reconhecê-la em nossas caminhadas cotidianas, para que possamos sair de nós mesmos e sempre, sempre nos assustar diante da violência contra um outro. A leitura é supérflua para quem tem fome permanente, afirma Rodrigo S.M. Sim, Clarice Lispector sabe que falar de Macábea é colocar-se em confronto permanente, 
reconhecer-se parte da engrenagem do sistema que mata a moça anônima. Sim, fica fácil falar do corpo na escrita por meio da escrita. Mas o som se dispersa, atinge cantos escondidos. A literatura pode mais, porque permite outros modos de sentir e de compreender o mundo.

\section{Bibliografia Citada}

CANGI, Ádrian. "Escribir el cuerpo: indícios, querelas y variaciones." In: SERRES, Michel. Variaciones sobre el cuerpo. Buenos Aires: Fondo de Cultura Económica, 2011.

LISPECTOR, Clarice. A hora da estrela. Rio de Janeiro: Francisco Alves, 1990.

NANCY, Jean-Luc. À escuta. Belo Horizonte: Chão da Feira, 2014.

RANCIÈRE, Jacques. Políticas da escrita. São Paulo: Editora 34, 2017.

LIBRANDI-ROCHA, Marília. "Escritas de ouvido na literatura brasileira." Literatura e Sociedade, no 19, 2015, p. 131-48. Disponível em: <https://doi.org/10.11606/issn.22371184.voi19p131-148>. Acesso em: 30 jul. 2019.

SERRES, Michel. Filosofia mestiça. Rio de Janeiro: Nova Fronteira, 1993.

2001.

Os cinco sentidos - Filosofia dos corpos misturados 1. Rio de Janeiro: Bertrand Brasil,

. Variaciones sobre el cuerpo. Buenos Aires: Fondo de Cultura Económica, 2011.

TAYLOR, Diana. O arquivo e o repertório: Performance e memória cultural nas Américas. Belo Horizonte: Editora UFMG, 2013.

\footnotetext{
'Pós-doutora, UFJF.

E-mail: liadumo@gmail.com
} 